Research Paper

\title{
Association of mSin1 with mTORC2 Ras and Akt reveals a crucial domain on mSin 1 involved in Akt phosphorylation
}

\author{
Chien-An Yao $^{1,2}$, Sara Ortiz-Vega ${ }^{3, *}$, Yun-Ya Sun ${ }^{1}$, Chiang-Ting Chien ${ }^{1}$, Jen-Hua \\ Chuang ${ }^{1, * *}$ and Yenshou Lin ${ }^{1}$ \\ ${ }^{1}$ Department of Life Science, National Taiwan Normal University, Taipei, Taiwan \\ ${ }^{2}$ Department of Family Medicine, National Taiwan University Hospital, Taipei, Taiwan \\ ${ }^{3}$ Diabetes Unit and Medical Services and The Department of Molecular Biology, Massachusetts General Hospital and \\ The Department of Medicine, Harvard Medical School, Boston, Massachusetts, USA \\ *Current address: San Juan, PR, Puerto Rico \\ *** Current address: Taipei Veterans General Hospital, Taipei, Taiwan \\ Correspondence to: Yenshou Lin, email: yenshoulin@ntnu.edu.tw
}

Keywords: mSin 1, mTORC2, Akt, Ras, association

Received: December 20,2016 Accepted: June 02, $2017 \quad$ Published: June 28, 2017

Copyright: Yao et al. This is an open-access article distributed under the terms of the Creative Commons Attribution License 3.0 (CC BY 3.0), which permits unrestricted use, distribution, and reproduction in any medium, provided the original author and source are credited.

\section{ABSTRACT}

mSin 1 is a unique component within the mammalian target of rapamycin (mTOR) complex 2 (mTORC2), which is responsible for cellular morphology and glucose metabolism. The association between $\mathrm{mSin} 1$ and other mTORC2 components, as well as their functions, has been explored previously; nevertheless, the mapping of the various binding domains of the components is lacking. Based on an evolutionary analysis of the gene, we constructed various fragments and truncated-forms of mSin1. We characterized the individual binding sites of $\mathbf{m S i n} 1$ with its various partners, including mTOR, Rictor, Ras, and Akt. mTOR and Rictor bind to the amino acid (aa) 100-240 region of $\mathrm{mSin} 1$, which is different to the Ras binding site, the aa 260-460 region. A reciprocal examination found that $\mathrm{mSin} 1$ associated with the aa $2148-$ 2300 region of $\mathbf{m T O R}$, which is within the kinase domain, and with the carboxyl terminus of Rictor. Interestingly, Akt was found to associate with $\mathrm{mSin} 1$ in a region that slightly overlapped with the mTOR/Rictor complex binding site, namely aa 220260. When only the Akt binding site was deleted from mSin 1, phosphorylation of Akt S473 was greatly reduced. Furthermore, the association between Akt and mTOR can be regulated by serum, insulin and LY294002, but not by rapamycin or MAPK kinase inhibitors. Taken together, $\mathrm{mSin} 1$ would seem to act as a hub that allows mTORC2 to phosphorylate Akt S473. Our findings should facilitate future proteomic and crystallographic studies, help the development of dominant inhibitors and promote the identification of new drug targets.

\section{INTRODUCTION}

The kinase mammalian target of rapamycin (mTOR) and its related signaling are closely associated with an organism's physiological and pathophysiological state, including cellular metabolism, survival, cell growth, proliferation, cell cycle, autophagy, aging, etc (see reviews [1-3]. Many drugs such as Sirolimus, Torin 1 and PP242 have also been developed to target
mTOR, as well as its downstream pathway, with the aim of targeting various cancers, diabetes, neurodegenerative diseases and aging [4-8]. The multiplicity of functions associated with mTOR are the partial result of the two physically distinct and separate hetero-oligomeric complexes found in cells; these are designated mTOR complex 1 (mTORC1) and mTOR complex 2 (mTORC2). mTORC1 contains three core polypeptides mTOR, Raptor (regulatory protein associated with 
mTOR) and mLST8 (mammalian lethal with Sec13 protein 8 ). On the other hand, the four core proteins that make up the mTORC2 complex are mTOR, mLST8, Rictor (rapamycin insensitive companion of mTOR) and mSin1 (mammalian SAPK interacting protein 1) [3]. In contrast to $\mathrm{mTORC} 1$, the upstream pathways, regulation and roles of $\mathrm{mTORC} 2$ are much less understood. Thus far, Akt/PKB, SGK1, and PKC $\zeta$ are the three substrates known to be directly phosphorylated by mTORC2 as part of its downstream signaling [9-12].

Within the mTORC2 complex, mSin 1, mammalian orthologue of Sin1, is indispensible to Akt phosphorylation [13-15]. The loss of $\operatorname{Sin} 1$ in $S$. pombe results in both impaired phosphorylation of the transcription factor Atf1 and a stress-sensitive phenotype that can be rescued by a fusion protein encoding the C-terminal 182 amino acids of chicken $\operatorname{Sin} 1$ [16]. Subsequent studies in mammalian cells have identified mSin1, also called Mip1, to be a MEKK2 binding protein that also binds SAPK/JNK [17, 18]. Interestingly, Schroder et al reported that $\mathrm{mSin} 1$ contains Raf-like Ras-binding domains (RBD) that are responsible for the binding to Ras [19]. Recently, it has been inferred that the $\mathrm{N}$-terminus of $\mathrm{mSin} 1$ is responsible for the binding of mSin 1 to mTORC2 [20]. While it has been clearly shown that $\mathrm{mSin} 1$ is an intrinsic component of mTORC2, published studies on $\mathrm{mSin} 1$ have not addressed in detail the regions involved in the binding of $\mathrm{mSin} 1$ to its various partners.

Mapping the binding domains between proteins has important implications; these include determining details of the binding mechanism, identifying possible specific activators/inhibitors, and facilitating the development of relevant drug targets. Based on a bioinformatics analysis of the mSin 1 evolution [21], we constructed a number of different fragments of $\mathrm{mSin} 1$ covering different $\operatorname{Sin} 1$ conserved domains (SCD) in order to study the various associations within the mTORC2 complex. Our findings not only have created a plausible three-dimension relationship among these proteins, but should also greatly help the development of new therapeutic strategies for the treatment of mTOR related diseases, in particular various cancers.

\section{RESULTS}

\section{mSin1 binds to the kinase domain aa 2148-2300 of mTOR}

Since mTOR is the major enzymatic molecule in the mTORC2, we initially examined the mSin 1 binding site within mTOR that retained its full length of 2549 amino acids. All amino terminus mTOR fragments shorter than aa 2191 did not bind, whereas the wild-type of mTOR did bind (Figure 1A); interestingly and logically, it was found that aa 2148-2549 of mTOR did associate with mSin1 (Figure 1B, lane 4). We further found that it is the kinase domain, aa 2148-2300, of mTOR that binds to $\mathrm{mSin} 1$ (Figure 1B, lane 2). Moreover, as shown in Figure
1C, FLAG tagged $\mathrm{mSin} 1$ is able to pull down HA tagged $\mathrm{mSin} 1$. Binding between FLAG-mTOR and HA-mSin1 was also included as a control. Since mTOR is capable of forming multimers, most likely dimers [22], we believe that our findings indicate that the association might be via either direct interaction or perhaps via indirect interaction that is mediated by mTOR dimerization.

\section{mSin1 binds to the carboxyl terminus aa 1181- 1708 of Rictor}

We confirmed the endogenous association and the effects of detergents on the mSin 1 and various mTOR complex component relationships [23]. As shown in the left panels of Figure 2A, Raptor, Rictor, and mSin1 antibodies individually are able to immunoprecipitate (IP) mTOR, whereas mSin 1 can only co-precipitate with Rictor and not with Raptor (lane 5). Conversely, Rictor antibody is able to pull-down mSin1 (lane 4), whereas Raptor antibody binds to neither of them. In parallel, the same experiment was executed in the presence of TritonX-100, as seen in the right panels of Figure 2A. Interestingly, while mTOR was washed away when the Rictor and $\mathrm{mSin} 1$ IPs were carried out, Rictor and $\mathrm{mSin} 1$ was still able to pull down each other (lane 9 and 10). This indicates that Rictor and mSin 1 are able to form a complex independent of mTOR. Furthermore, it has been previously showed that the RNAi of Rictor and of $\mathrm{mSin} 1$ is able to bring about a decrease in PKB/Akt S473 phosphorylation independently $[12,14]$. In addition, confirming these findings, it was found that both Rictor and $\mathrm{mSin} 1$ proteins are decreased in Rictor knock-down cells (Figure 2B). Nevertheless, only the abundance of $\mathrm{mSin} 1$ protein, but not the abundance of Rictor protein, is affected in mSin1 RNAi knockdown cells. This implies that the interaction between $\mathrm{mSin} 1$ and Rictor might not be a mutual dependent one. We further examined the $\mathrm{mSin} 1$ binding site within Rictor that was full length at 1708 amino acids. Based on SMART analysis (http:// smart.embl-heidelberg.de/), Rictor protein contains few identifiable regions except for a RasGEF $\mathrm{N}$ domain in the region aa 743-857. Thus we simply divided this protein into three fragments based on a bioinformatics analysis. Unfortunately the aa 861-1180 fragment was found not to be expressed at all. However, using the two other fragments, as shown in the Figure $2 \mathrm{C}$, we found that only the aa 1181-1708 fragment was able to bind to mSin 1 . Hence, it would seem that the carboxyl terminus of Rictor, but not amino terminus, is involved in binding to $\mathrm{mSin} 1$.

\section{mSin1 binds to $\mathrm{mTOR} /$ Rictor via $\mathrm{mSin} 1$ aa 100-240}

We began by mapping the binding sites of $\mathrm{mSin} 1$ that was full length at 522 amino acids in relation to the various individual components found within the mTORC2 complex. Initially, HEK 293T cells were co-transfected 
A

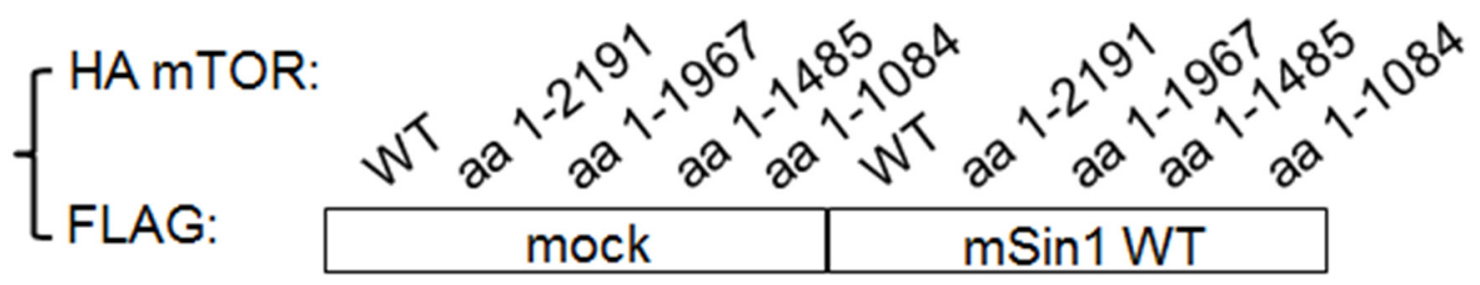

FLAG-IP:

$\alpha \mathrm{HA}$

Extract:
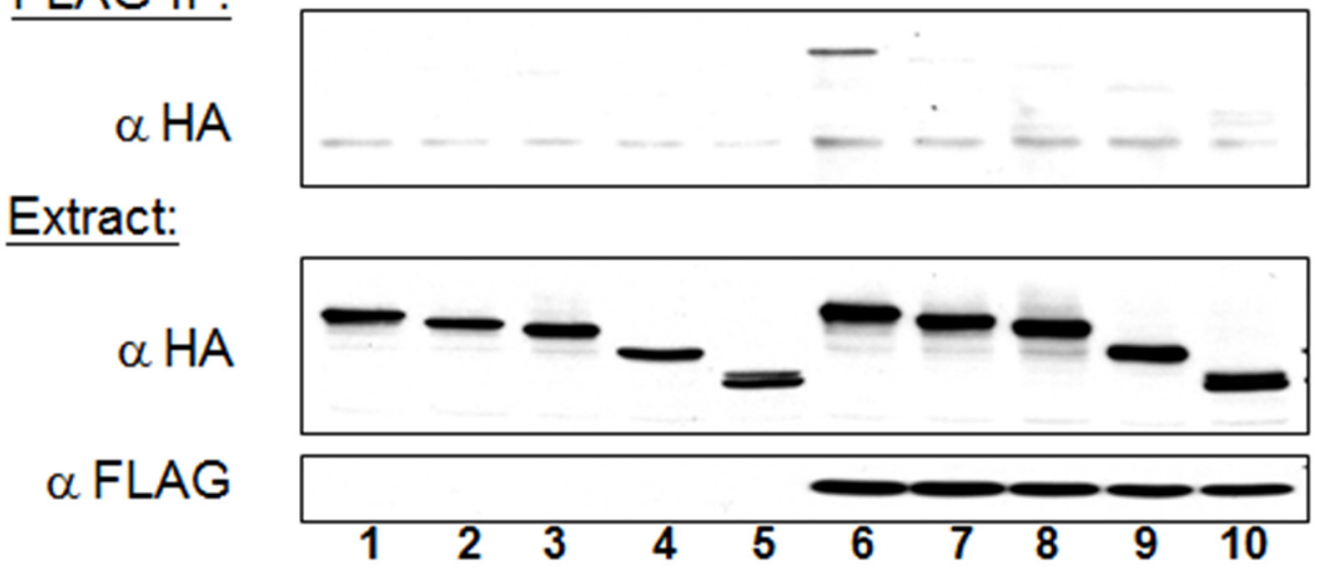

B

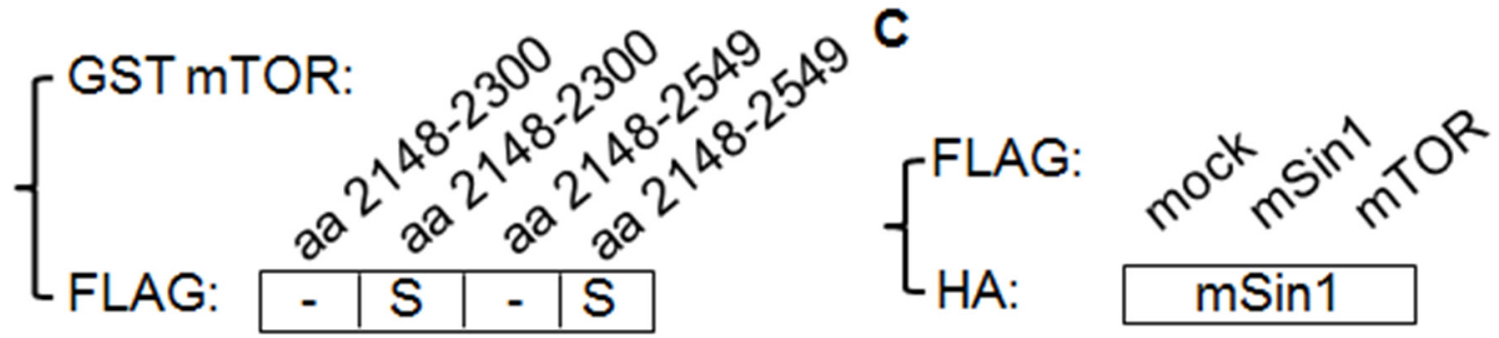

FLAG-IP:

GST

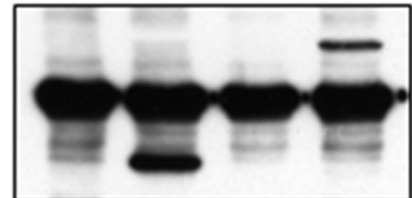

Extract:

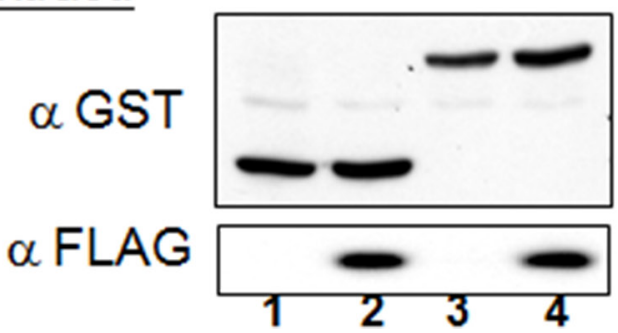

FLAG-IP:

$\alpha \mathrm{HA}$

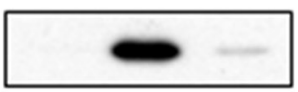

Extract:

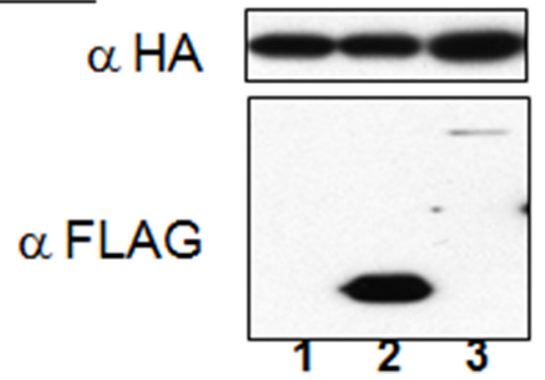

Figure 1: mSin1 binds to the kinase domain of mTOR. (A) HEK 293T cells were co-transfected with indicated FLAG/FLAGmSin1 and HA-mTOR plasmids (full length, aa 1-2191, 1-1967, 1-1485, and 1-1084). The expressed proteins from the lysate were subjected to FLAG antibody IP. (B) HEK 293T cells were co-expressed with FLAG-mSin1 wild-type (S) and GST-mTOR fusion proteins (aa 2148-2300 and aa 2148-2549). The cells were lysed and the supernatants were performed FLAG antibody IP. (C) HEK 293T cells were co-transfected with indicated FLAG/FLAG-mSin1/FLAG-mTOR and HA tagged mSin1. The expressed proteins from the lysate were subjected to FLAG antibody IP and Western blot analysis. Anti-FLAG, anti-HA, or anti-GST antibodies were used to detect appropriate proteins in the total lysates, the IP samples, and pull-down samples. The blots are representative of one experiment repeated twice. 
with tagged mSin1 along with individual tagged recombinant genes (Supplementary Figure 1). We soon found that a single transfection of FLAG tagged mSin 1 followed by FLAG IP showed the same level of robust binding of the various endogenous partners as the ones obtained using co-transfection. Therefore, the associated mTORC2 components shown in Figure 3 are the endogenous proteins detected by blotting using appropriate individual antibodies. The expression of the individual endogenous proteins as well as FLAG-mSin 1 full length and its various fragments are shown in the Figure $3 \mathrm{~A}$. As shown in the Figure 3B, mSin 1 aa 1-314 and aa 1-460, but not aa 1-123, are each capable of associating with $\mathrm{mTOR} /$ Rictor/mLST8. The association between mSin1 and the

A

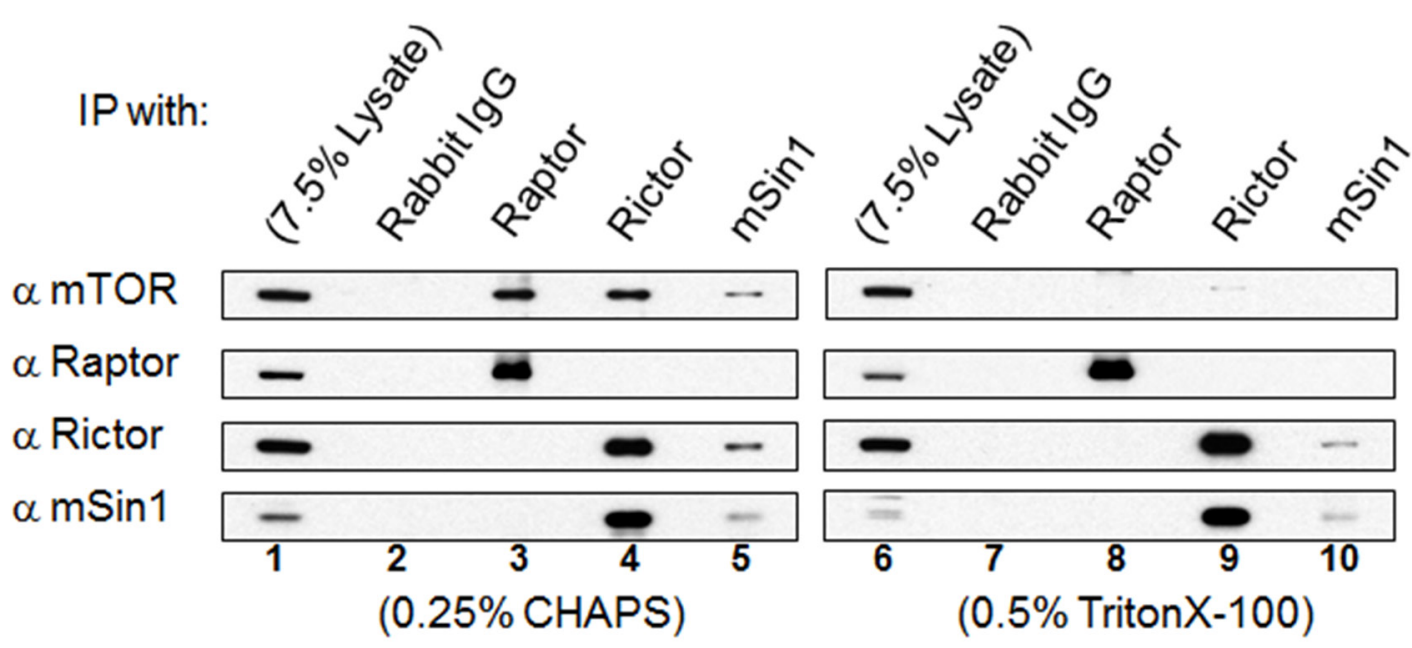

B

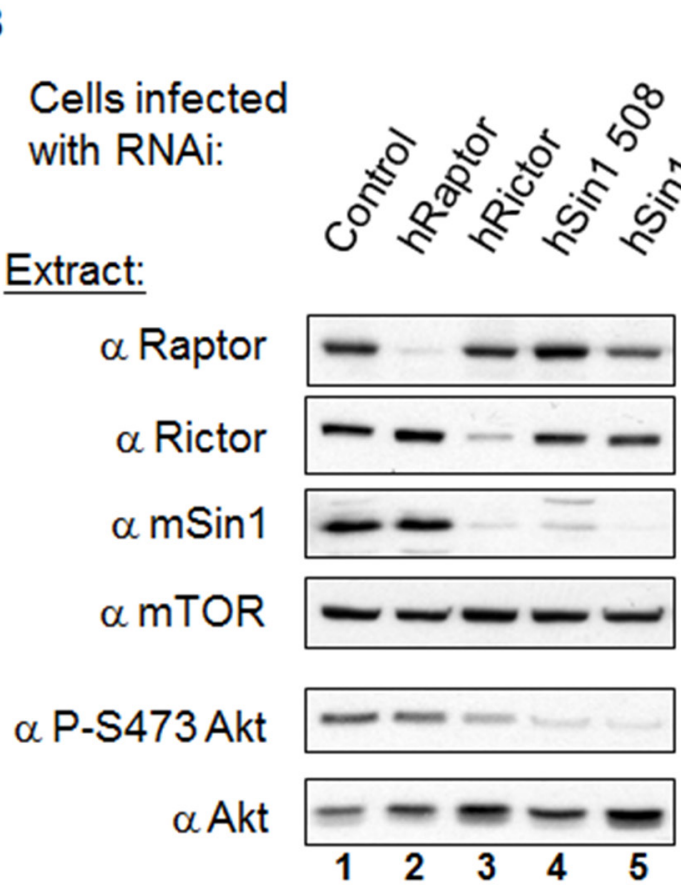

C
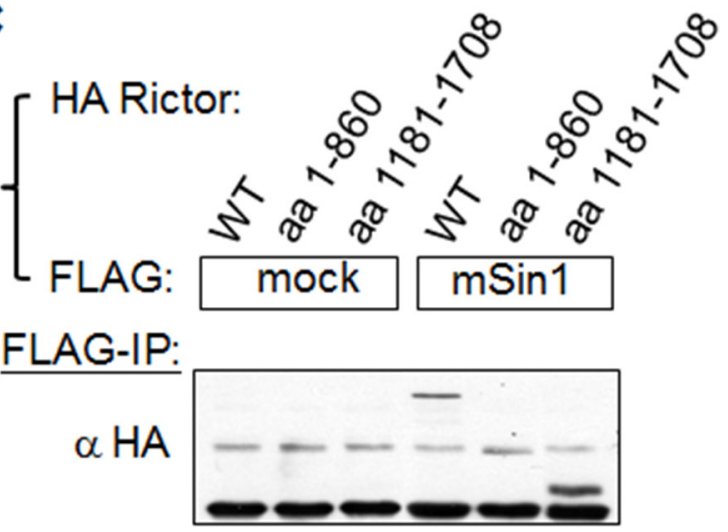

Extract:

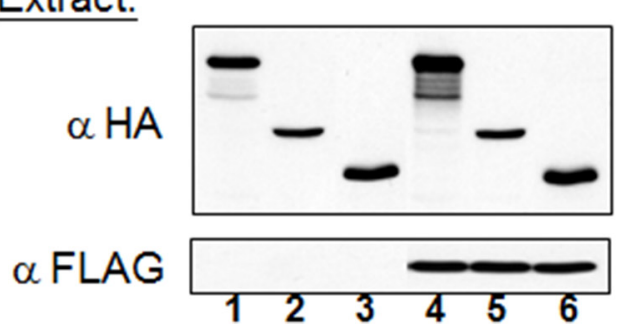

Figure 2: mSin1 forms a stable complex with Rictor independent of $\mathbf{m T O R}$ and binds to the carboxyl terminus of Rictor. (A) HEK 293T cells were lysed in buffer containing $0.25 \%$ CHAPS (left panels) or 0.5\% Triton X-100 (right panels). Antibodies against mTORC1 or mTORC2 were used to perform IP or reciprocal IP. (B) Viral particles containing Raptor, Rictor or two types of mSin1 RNAi were used to infect HEK 293T cells. Cells infected with luciferase RNAi were included as a control. The lysates were processed by Western blot analysis to detect the various proteins, Akt abundance and the phosphorylation of Akt S473 (P-S473 Akt). (C) HEK 293T cells were co-transfected with the indicated FLAG/FLAG-mSin1 and HA tagged Rictor plasmids (full length, aa 1-860 and 1181-1708). The expressed proteins were subjected to FLAG antibody IP. Anti-FLAG and anti-HA antibodies were used to detect the appropriate proteins in the total lysates and in the IP samples. The blots are representative of one experiment repeated twice. 
A

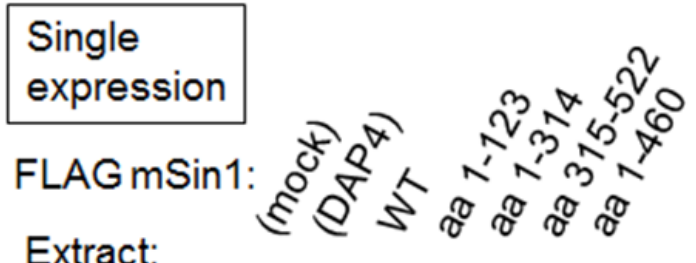

Extract:

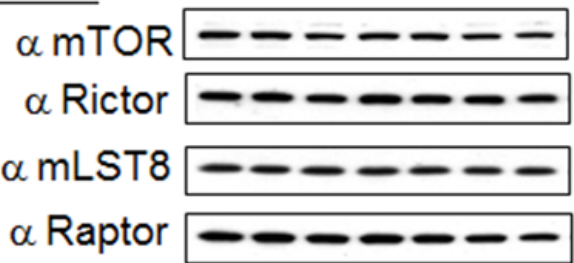

FLAG-IP:

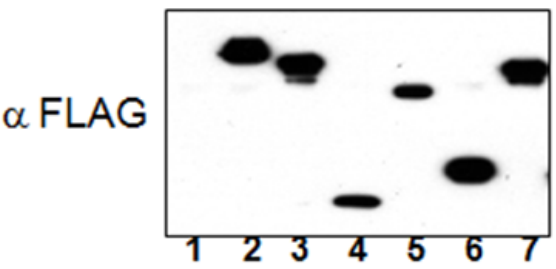

D

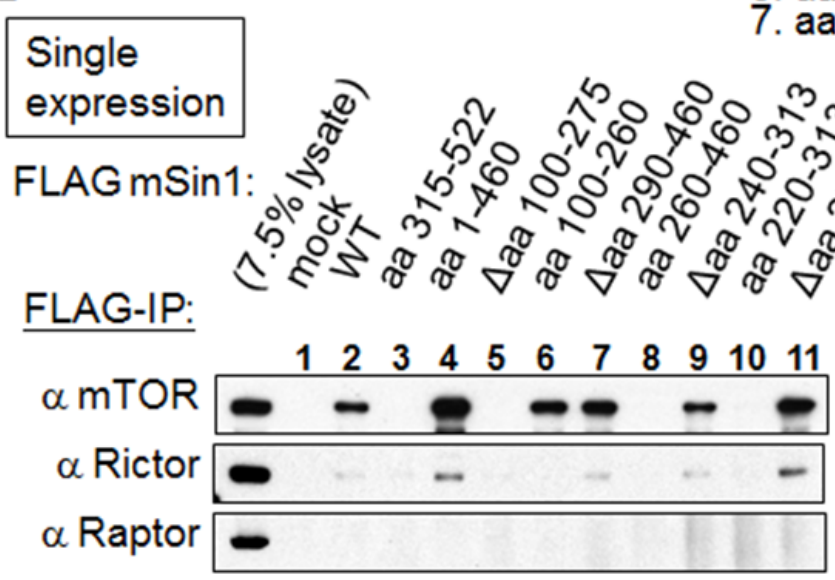

\section{Extract:}

$\alpha$ FLAG

B

C

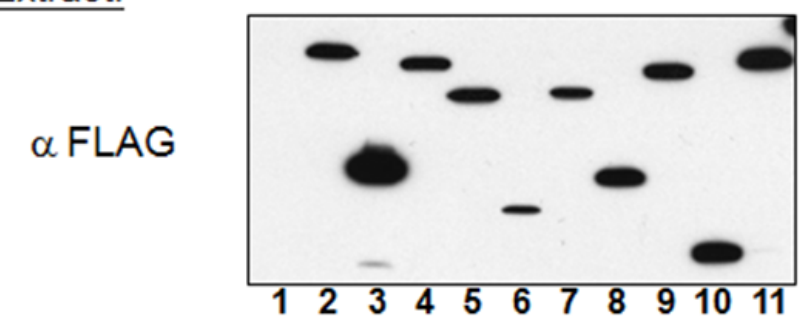

FLAG-IP
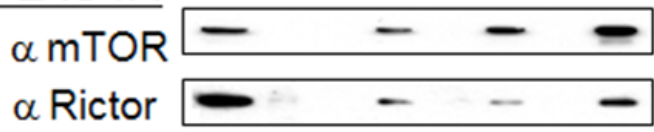

$\alpha \mathrm{mLST8}-\mathrm{m}$ -
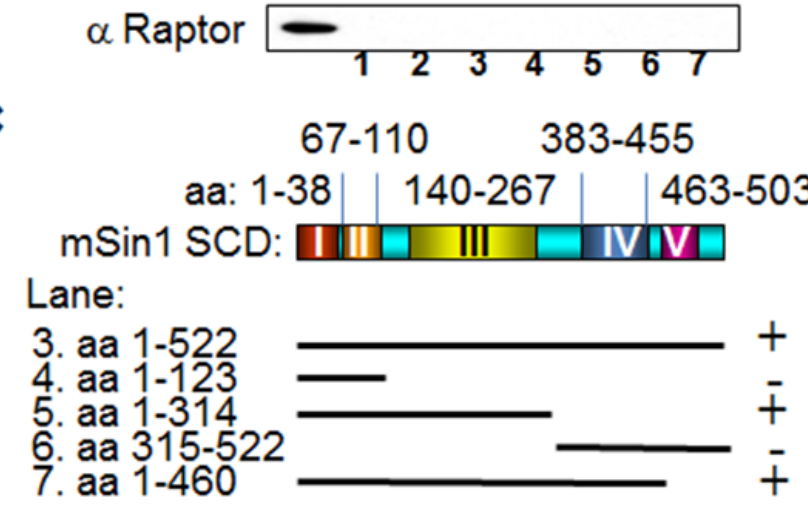

\section{$i^{3} \mathrm{E}$} 67-110 383-455 aa: $1-38 \mid$ | 140-267 | 463-503 SCD: \begin{tabular}{|l|l|l|l|l|} 
III & IIV & IV V \\
\hline
\end{tabular}

\section{Lane:}

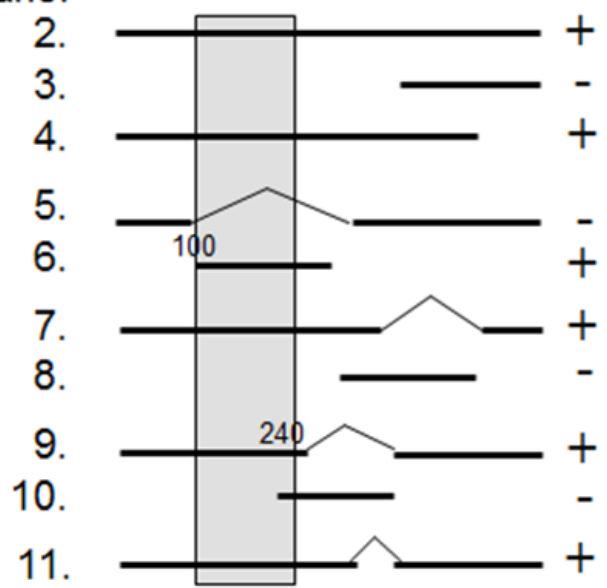

Figure 3: mSin1 aa 100-260 binds to mTOR/Rictor. (A) and (B) HEK 293T cells were individually transfected with various forms of FLAG-mSin 1 (aa 1-123, 1-314, 315-522, 1-460, and wild-type). The expressed proteins from the lysate were subjected to FLAG antibody IP. Anti-mTOR, Rictor, mLST8, and Raptor antibodies were used to assess/detect the appropriate protein levels in the total lysates and in the IP samples. Both FLAG only (mock) and FLAG tagged death associated protein 4 (FLAG-DAP4) were included as negative controls. (C) The binding between the various fragments of $\mathrm{mSin} 1$ and the different endogenous proteins is summarized. The recovery of the mTOR/Rictor/ mLST8 together with mSin1 fragments including different Sin1 conserved domains (SCD) is indicated on the right as either + or -. (D) After more experiments of trials and errors, HEK 293T cells were individually transfected with the indicated FLAG-mSin1 WT or FLAG-mSin1 fragments. The expressed proteins from the lysate were subjected to FLAG antibody IP and Western blot analysis. Indicated antibodies were used to detect the appropriate associated proteins in the total lysate and in the IP. (E) The recovery of endogenous mTOR with the fragments of $\mathrm{mSin} 1$ is summarized and indicated on the right as either + or - . The blots are representative of one experiment repeated twice. 
endogenous mTORC2 components is schematically presented in Figure 3C. The findings suggest that the binding site is within aa 123-314. After testing over several rounds and adjusting/constructing proteins consisting of a range of different regions within $\mathrm{mSin} 1$, it was possible to map the shortest fragment to the range aa 100-260 within $\mathrm{mSin} 1$ as seen in Figure 3D. All the mutants that encompass this region were found to be capable of binding to endogenous mTOR (Figure 3D). Conversely, mutants that lack this region, for example $\Delta$ aa 100-275 in lane 5, were unable to bind endogenous mTOR. Based on these findings, the fragment of $\mathrm{mSin} 1$ involved in endogenous Rictor binding would also seem to be located within the region aa 100-260 because the pattern obtained is similar to that for mTOR binding. A Raptor blot is included as a comparison. However, since the Rictor pull-down is not so obviously visualized using the $\mathrm{mSin} 1$ fragment aa 100-260, in contrast to other variants, it is possible that Rictor might need a larger domain, such as aa 1-260 of $\mathrm{mSin} 1$, to form a tight association. The associations between the various mSin 1 fragments and mTOR/Rictor are summarized in Figure 3E. We infer from these results that the shortest region of $\mathrm{mSin} 1$ capable of undergoing endogenous mTOR binding is the area around aa 100-240 (lanes 6, 9 in Figure 3E).

\section{mSin1 binds to active HaRas, but not other active Ras superfamily members, via the $\mathrm{mSin} 1$ aa 260-460 region}

Sin 1 has been reported to preferentially bind to the GTP-bound form of Ras in Dictyostelium [24]. Schroder et al. also found that a similar effect occurred in mammalian cells [19]. Intriguingly, we found that HaRas G12V shows a strong association with $\mathrm{mSin} 1$, but that there was no similar association with either Rap $1 b$ G12V or Rho G14V, as is shown in Figure 4. We then mapped the binding site and found that the $\mathrm{mSin} 1$ aa $260-460$ is able to associate with HaRas G12V (Figure 5A). No binding occurred when the mSin 1 mutant lacking this region was

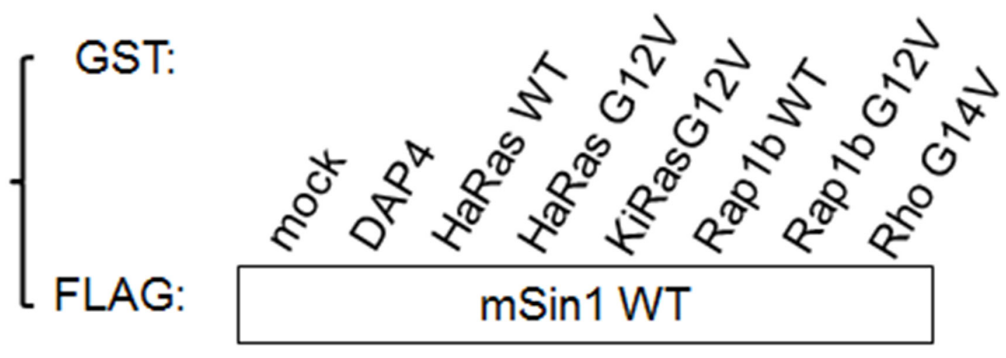

GSH Pull D.:

$\alpha$ FLAG

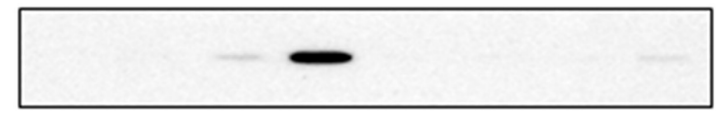

\title{
Extract:
}

\author{
$\alpha$ FLAG
}
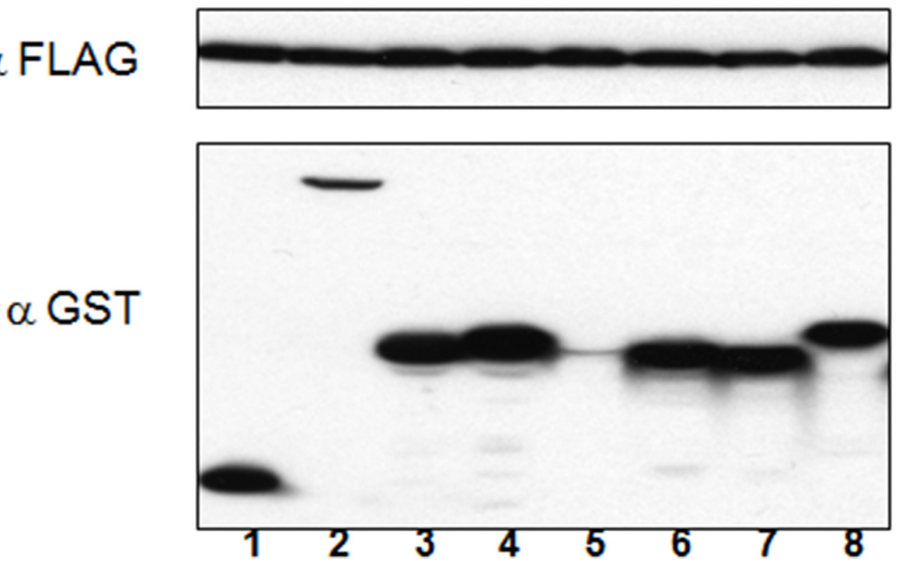

Figure 4: Active Ras, but not other active forms of members of the Ras superfamily, is able to bind to mSin1. HEK $293 \mathrm{~T}$ cells were co-transfected with the indicated FLAG-mSin1 WT and with various GST tagged plasmids, namely HaRas WT, HaRas G12V, KiRas G12V, Rap1b WT, Rap1b G12V and Rho G14V. The expressed proteins from the lysate were analyzed by Western blotting using anti-FLAG and GST antibodies. After the lysates were subjected to GSH pull down, anti-FLAG antibody was used for the Western blot analysis. The blots are representative of one experiment repeated twice. 
used. However, the expression of the mSin aa100-260 is quite low compared to the other mSin mutants. As a result of this, we place a caveat on the above and suggest that instability may be the reason for the low expression. The association between the various $\mathrm{mSin} 1$ fragments and active HaRas is summarized in Figure 5B. Based on these findings, we believe that the binding site for $\mathrm{mSin} 1$, when it associates with active HaRas, is located within the aa 260-460 region which contains SCD IV (i.e. aa 383-455). Furthermore, we also have shown that a mutant lacking aa 290-460 significantly impairs the phosphorylation of SAPK (Supplementary Figure 2).

\section{mSin1 binds to Akt/PKB via mSin1 aa 220-260}

mTORC2 has been proposed to function as a PDK2 and phosphorylate Akt at S473 [12, 14]. Based on this we examined whether Akt is able to associate with $\mathrm{mSin} 1$. Using the constructs made up of the various regions of mSin1, we mapped the Akt binding site to be located in the region aa 220-260 of mSin1 (Figure 6A). Any fragments, such as aa 220-313, that include this region, also show an association (lane 10). By way of contrast, proteins lacking this region, for example $\Delta$ aa 240-313 in lane 9, are unable to bind Akt. The association between the various mSin 1 fragments and Akt is summarized in Figure $6 \mathrm{~B}$. These findings imply that the binding site within $\mathrm{mSin} 1$ for Akt is located in the region aa 220-260 (lanes 6,9 and 10 in Figure $6 \mathrm{~B}$ ). This region is quite distinct from the main binding sites for the other components that form the mTORC2 complex and involved in active HaRas association. In addition, we also reciprocally mapped where the sites of Akt binds to mSin1. As shown in Figure 6C, Akt aa 1-107, but not aa 149-480, binds to mSin1. This indicates that it is the pleckstrin homology domain (PH domain) of Akt, and not the kinase domain, which is capable of binding to $\mathrm{mSin} 1$.

\section{The association between Akt and mTOR is regulated by serum, insulin and the PI3K inhibitor LY294002}

We next examined the possible binding-associated functional relationship between $\mathrm{mSin} 1$ and $\mathrm{mTORC} 2$.
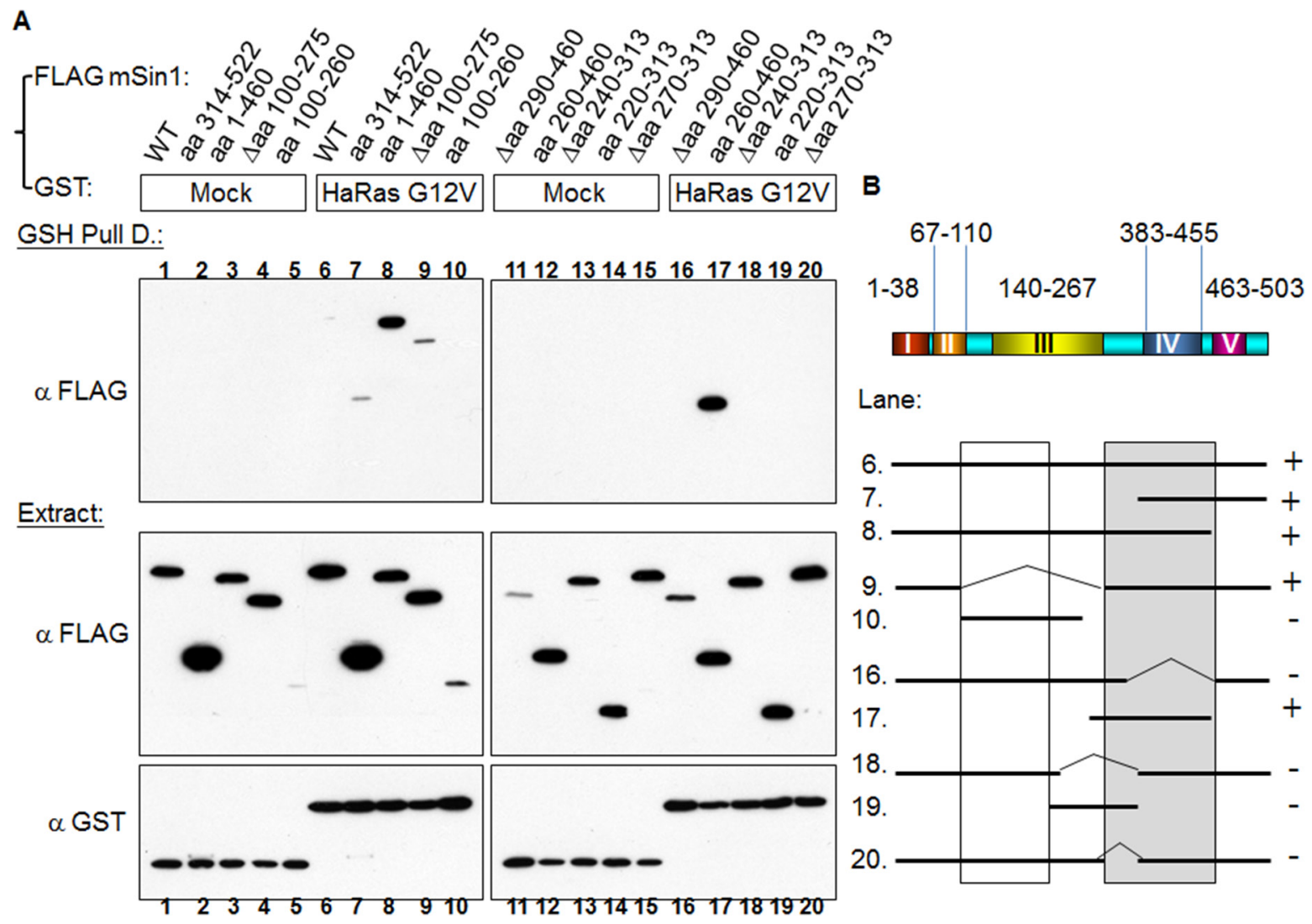

Figure 5: HaRas G12V binds to $\mathrm{mSin} 1$ aa 260-460, a region that is different to the one involved in $\mathrm{mTORC2}$ binding. (A) HEK $293 \mathrm{~T}$ cells were co-transfected with GST/GST-HaRas G12V and the various indicated FLAG-mSin1 fragments. A portion of each extract was used to examine the expression level of the GST and FLAG tagged proteins. The majority of each lysate was subjected to GSH pull down. Anti-FLAG antibody was used to detect the associated proteins after the pull-down. (B) The binding between fragments of $\mathrm{mSin} 1$ and the recombinant HaRas G12V proteins is summarized here. The recovery of the HaRas G12V association is indicated on the right as either + or - . The blots are representative of one experiment repeated twice. 
Overexpression of $m \operatorname{Sin} 1 \Delta$ aa 100-275 (lane 4) resulted in a dramatic decrease in phosphorylation at endogenous Akt S473 when the expression of these fragments was at similar level (Figure 7A). In the same experiment, HEK $293 \mathrm{~T}$ cells were subjected to normal serum (lane 10) or serum starvation for $16 \mathrm{~h}$ followed by treatment with 100 nM-1 $\mu \mathrm{M}$ insulin for 0 (lane 11) and $20 \mathrm{~min}$ (lane 12). We used these treatments to verify the authenticity and specificity of the antibodies used. This finding implies that the mTORC2 complex and its substrate Akt might need to bind to a particular region on $\mathrm{mSin} 1$ in order to assemble a functional unit. On the other hand, fragments lacking mTOR/Akt binding, such as mSin 1 aa 314-522, do not have such an effect. We interpret this to mean that $\mathrm{mSin} 1$ $\Delta$ aa $100-275$ is a special mutant that fulfills the criteria of having a dominant negative function, while the other mutants do not have this ability.

In addition to the above, we also examined whether the enzyme-substrate complex formed between mTORC2 and Akt undergoes regulation by various factors. Using a pull-down approach, we found that GST Akt is able to pull down endogenous mTOR (Figure 7B). The association between mTOR and Akt is disrupted by treatment with the PI3 kinase inhibitor LY294002, but is not affected by the mTOR inhibitor rapamycin or the MAPK inhibitor U0126 (Figure 7B). Furthermore, the amount of associated mTOR is decreased when the cells are subjected to the overnight serum withdrawal. Interestingly, this attenuation of the association can be reversed by adding insulin back into the culture medium (Figure 7C).

\section{DISCUSSION}

During the present study, we have pinpointed the binding sites that allow interactions between $\mathrm{mSin} 1$ and mTOR, Rictor, Ras and Akt. We found that it is the kinase domain of mTOR, carboxyl terminus of Rictor, and $\mathrm{PH}$ domain of Akt that bind to $\mathrm{mSin} 1$. The binding site for

A
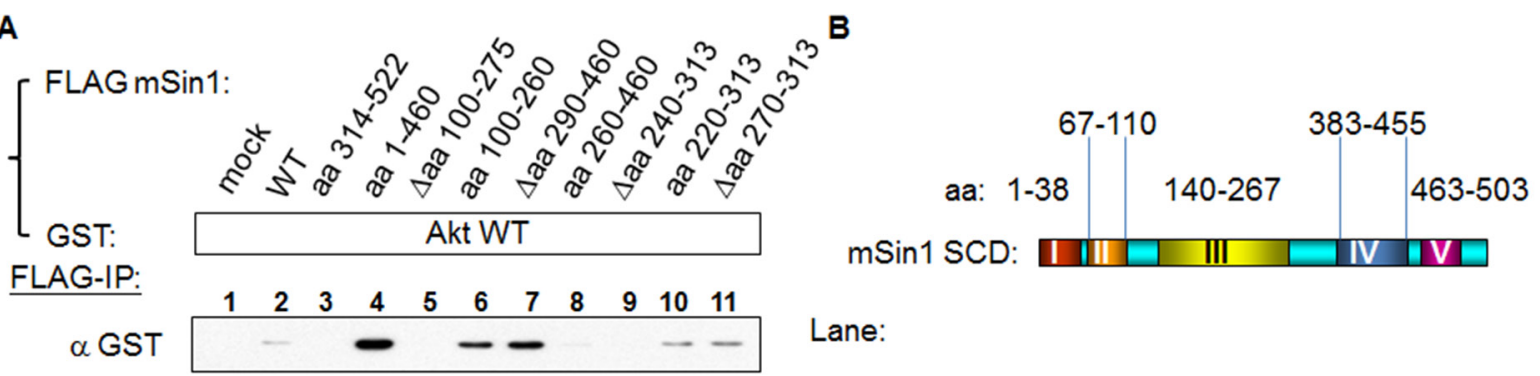

Extract:

$\alpha$ GST

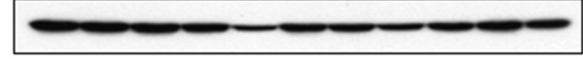

$\alpha$ FLAG

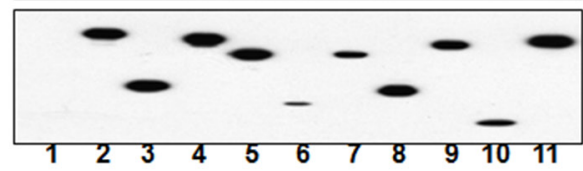

C

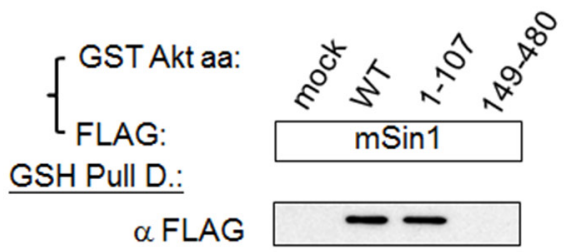

ane:

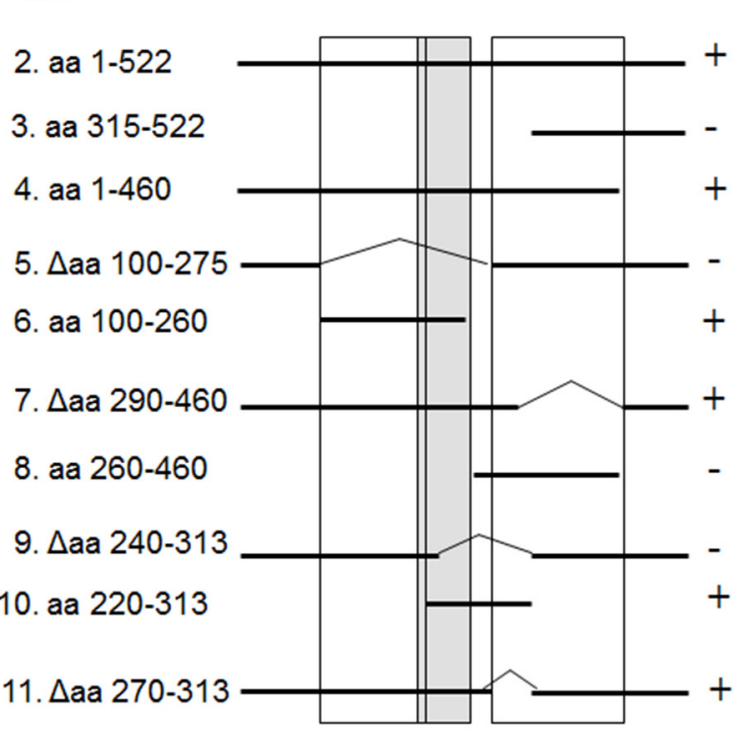

Figure 6: Akt binds to $\mathrm{mSin} 1$ aa 220-260, a region between the $\mathrm{mSin} 1$ binding site for mTOR/Rictor and for HaRas. (A) HEK 293T cells were co-transfected with the various indicated FLAG-mSin1 fragments and GST-Akt WT. A portion of each extract was used to examine the expression levels of the FLAG and GST tagged proteins. The majority of each lysate was subjected to FLAG antibody IP. Anti-GST antibody was used to detect the present of the various associated proteins after the IP. (B) The binding between the various recombinant fragments of $\mathrm{mSin} 1$ and recombinant Akt protein is summarized. The recovery of Akt association is indicated on the right either as + or -. (C) HEK 293T cells were co-transfected with the indicated FLAG-mSin1 and GST tagged Akt plasmids (full length, aa 1-107 and 149-480). The expressed proteins were subjected to GST pull-down. Anti-FLAG and anti-GST antibodies were used to detect the appropriate proteins in the total lysates and in the pull-down samples. The blots are representative of one experiment repeated twice. 
Akt on $\mathrm{mSin} 1$ is adjacent to the site for $\mathrm{mTOR} /$ Rictor binding and is crucial for the phosphorylation of Akt at S473 by the mTOR kinase. Importantly, the association/ dissociation between Akt and mTOR can be regulated by serum and insulin and this is mediated via the PI3K pathway.
Frias et al observed that the mSin 1 isoform 4, which lack the first 192 amino acid residues, does not bind to mTORC2, while the other isoforms do bind [13]. They proposed that aa 1-192 within mSin 1 allows binding to mTORC2. However, we found initially that the region aa 1-123, which contains SCD I and SCD II, is not able to

A

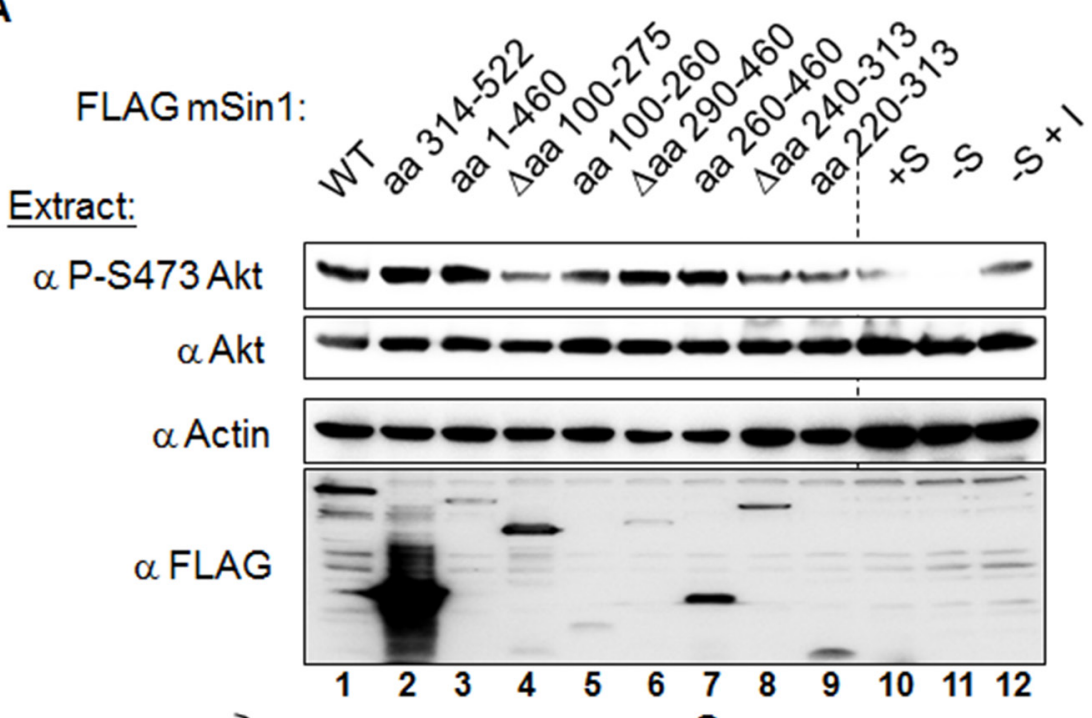

B

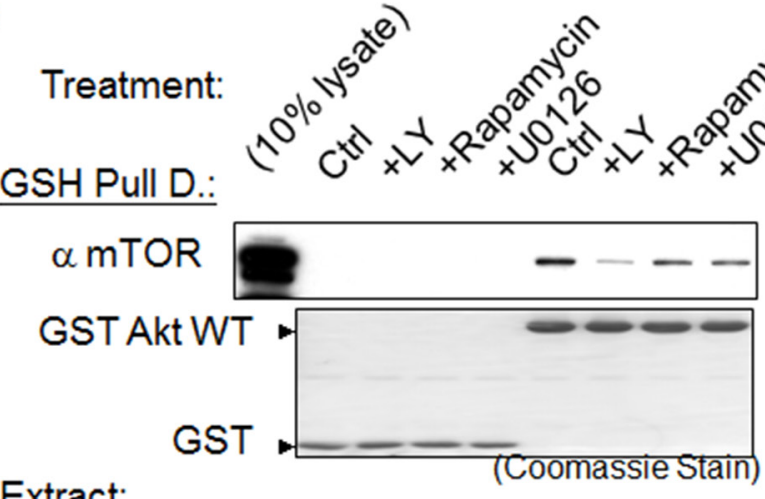

Extract:

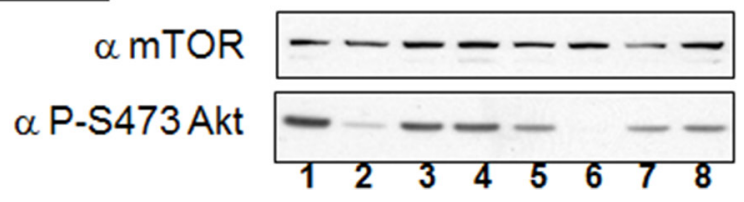

C

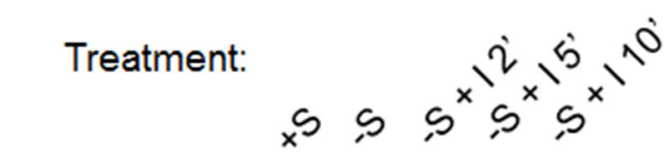

GSH Pull D.:

$\alpha$ mTOR

GST Akt WT

Extract:
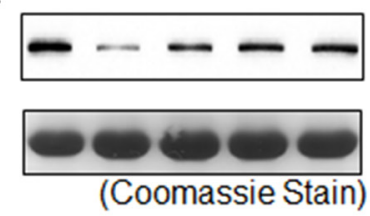

$\alpha \mathrm{mTOR}$

$\alpha$ P-S473 Akt

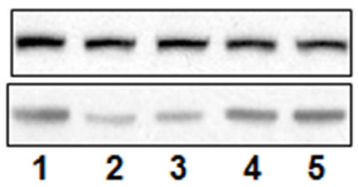

Figure 7: The mSin1 aa 100-275, namely the binding sites for mTORC2 and Akt, is necessary for phosphorylation of Akt at the $\mathbf{S 4 7 3}$ site. The association between mTOR and Akt can be regulated by serum, insulin and the presence of a PI3K inhibitor. (A) HEK 293 T cells were only transfected with the various indicated FLAG-mSin1 fragments. Cells were lysed in the lysis buffer containing $0.5 \%$ TritonX-100. Anti-phosphorylated Akt S473 antibody was used to detect the functioning of these mSin1 fragments. The last three lanes (lane 10,11, and 12) were cells treated with normal serum $(+\mathrm{S})$, serum withdrawal $(-\mathrm{S})$, or insulin stimulation after serum withdrawal $(-\mathrm{S}+\mathrm{I})$ and the Akt signaling changes were used as the antibodies efficacy controls. (B) HEK 293T cells were transfected with either GST or GST Akt. Twenty-four hours after transfection, the cells from the master culture were split into individual plates so that the starting material was the same. Sixteen hours after the split and before the cells were harvested, the cells were treated with vehicle DMSO, $20 \mu \mathrm{M}$ LY294002, $1 \mu \mathrm{M}$ rapamycin, or $10 \mu \mathrm{M}$ U0126 for $1 \mathrm{~h}$. (C) HEK 293T cells were transfected with GST Akt. Twenty-four hours after transfection, the cells from master culture were split into individual plates so that the starting material was the same. The cells were then either continuously cultivated in medium containing serum $(+\mathrm{S})$ or in serum depletion medium (-S), both for an additional $16 \mathrm{~h}$. Immediately before harvesting these groups of cells, insulin $1 \mu \mathrm{M}$ was added into the medium for an additional 2, 5, or $10 \mathrm{~min}$. After processing by GST pulling down and Western blot analysis, antibodies such as anti-GST, mTOR, and phosphorylated S473 Akt were used to detect the signal. The blots are representative of one experiment repeated twice 
associate with mTOR and/or mLST8 during our initial attempt to map the binding sites (Supplementary Figure 1). This discrepancy was part of our rationale for initiating this study. After more detailed mapping of the region, we found that the region aa 100-260 of $\mathrm{mSin} 1$ is the one able to bind to $\mathrm{mTORC} 2$ and this covers the SCD III region aa 140-267. The aa 100-260 of $\mathrm{mSin} 1$ also corresponds to the CRIM region aa 137-266, a region named after "conserved region in the middle" of all proteins in the Sin 1 family [25]. This CRIM region is also known to associate with $\mathrm{PKC} \alpha$ and PKC $\varepsilon$ [20]. Specifically, Cameron et al mapped the site to be within the aa 193-320 region of $m \operatorname{Sin} 1$. In addition, we found the binding site between Akt and $\mathrm{mSin} 1$ is within the aa $220-260$ region of $\mathrm{mSin} 1$. Since the direct substrates of mTORC2 are thought to be Akt [12], PKCs [11, 26], and SGK1 [9], our findings suggest that there might be only trivial differences among the bind sites for these AGC kinases when they interact with the SCD III region. Interestingly, the phenomenon that $\mathrm{mSin} 1$ aa $1-460$ always has a better binding ability toward mTOR/Rictor/ Akt compared to mSin 1 wild-type indicates that the SCD $\mathrm{V}$ (aa 464-503) might have some inhibitory effect on this association.

When $\mathrm{mSin} 1$ aa $100-260$ is absent, $\mathrm{mSin} 1$ is unable to bind to mTORC2 and Akt. Although mTOR is a large polypeptide and has multiple domains within the protein, $\mathrm{mSin} 1$ seems to associate with the mTOR kinase domain. Thus $\mathrm{mSin} 1$ might function as a scaffold protein that brings Akt, the substrate of mTOR, into a compact conformation that is able to be phosphorylated at its S473 residue. The binding sites between mTOR/ Rictor and Akt on mSin1 are adjacent, which seems likely to create a conformation that allows mTORC2 to function as a PDK2. Supporting this hypothesis, $\mathrm{mSin} 1$ $\triangle$ aa 100-275, which lacks the Akt binding site, does show a dramatic decrease in Akt S473 phosphorylation. This could provide fundamental and useful information for the solving of the three-dimension structure of the mTORC2. In addition, mSin $1 \Delta$ aa 100-275 demonstrates a unique character with respect to decreasing Akt S473 phosphorylation with no other fragments have a similar effect. Therefore, the criteria for $\mathrm{mSin} 1$ mutants to be a dominant negative fragment in terms of Akt phosphorylation might be that they need to strictly fulfill all associations except for those with the mTOR and Akt proteins. Knowledge of this specificity probably enhances the possibility of developing inhibitory drugs that are able to block the phosphorylation and/or activation of the oncogene Akt.

Sin 1 in Dictyostelium binds to RasG Q61L, but not RasG S17N [24]. This mutant in the Ras binding domain (RBD) has been found to greatly impair Dictyostelium chemotaxis/aggregation [27]. As part of the present study we have found that active HaRas binds to mSin 1 at a totally separated domain to that of mTOR/Rictor and Akt. It has been reported that $\mathrm{mSin} 1$ contains a Ras binding domain and a pleckstrin homology domain and is able to suppress Ras signaling [19]. Therefore, the different binding sites of $\mathrm{mTOR} /$ Rictor/Akt/HaRas on $\mathrm{mSin} 1$ might plausibly create a range of different complexes in response to various different stimuli, which would in turn result in $\mathrm{mSin} 1$ being able to mediate control of multiple pathways. Recently, it has been reported that $\operatorname{Sin} 1 \gamma$, a $\mathrm{mSin} 1$ isoform, is able to interact with the components
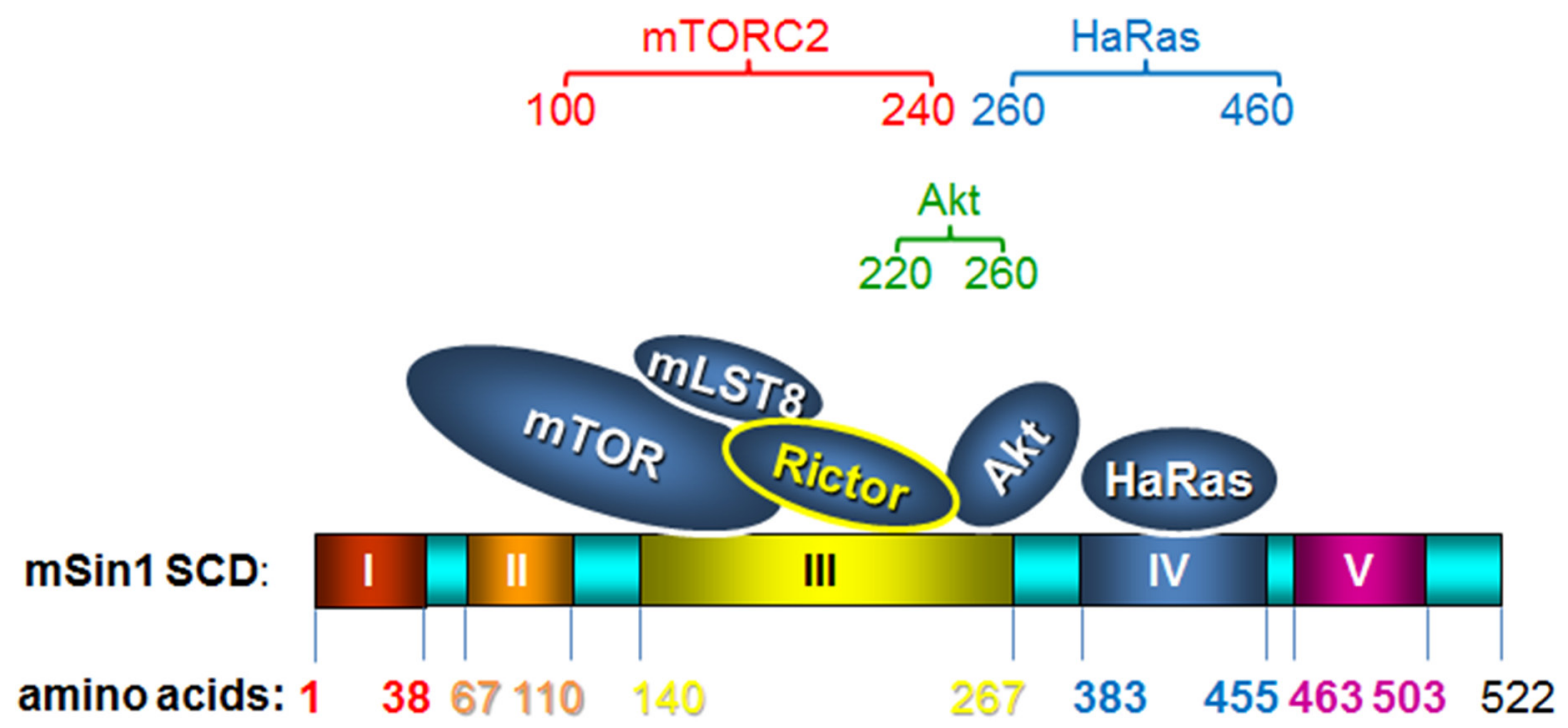

Figure 8: A cartoon schematically presenting how mSin1 associates with its various partners. It is the kinase domain of mTOR, the carboxyl terminus of Rictor, and the pleckstrin homology domain of Akt that bind to mSin 1 . Based on these findings in terms of association between the various proteins and the various fragments of mSin1, we suggest that mTORC2, Akt, and HaRas, respectively, associate with $\mathrm{mSin} 1$ aa $100-240, \mathrm{mSin} 1$ aa $220-260$, and $\mathrm{mSin} 1$ aa $260-460$. 
that form the mTORC2 complex, but does not seem to participate in the functioning of $\mathrm{mTORC} 2$ with respect to the phosphorylation of Akt S473 [28]. Obviously, it is clear that the different regions as well as the various isoforms of $\mathrm{mSin} 1$ are likely to contribute to a range of effects on signal transduction within cells.

Typically, protein-protein interactions are a central concept of signaling transduction, although protein-lipid and other forms of interaction are also likely to play roles [29]. It has been proposed that Akt activation by growth factors is due to the recruitment of PDK1 and Akt to the membrane via their PH domains [12, 30, 31]. At the membrane, Akt T308 and S473 were respectively phosphorylated by PDK1 and mTORC2. Here, we have provided a further possibly regulatory mechanism whereby a decrease in Akt S473 phosphorylation caused by serum withdrawal might simply occur via the dissociation of Akt from the mTORC2.

In summary, we provide in this study a structure/ function analysis describing the proteins interaction between mTORC2, Ras, Akt and mSin1. The association between mTOR and Akt can be regulated by insulin and serum. Such enzyme-substrate binding is blocked by a PI3K inhibitor, but not by either rapamycin or a MAPK inhibitor. The binding process is depicted schematically as Figure 8, which shows how $\mathrm{mSin} 1$ bind to its various partners using different regions within the protein. These findings provide fundamental information that will help our understanding of the three-dimension topography of the mTORC2, especially how the enzyme, the scaffolding and the substrate(s) interact. The results also facilitate our greater understanding of this complex proteomic/signaling network. Furthermore, the regions we have mapped should help with the development of drug targets and/or inhibitors that are relevant to a number of diseases including cancer.

\section{MATERIALS AND METHODS}

\section{Reagents}

The materials/reagents were purchased from the companies indicated in parentheses: Dulbecco's modified Eagle's medium (DMEM, Gibco-BRL-Life Technologies, NY, USA); fetal bovine serum (FBS, Thermo Scientific, Utah, USA); protein G-agarose and protein A-agarose, antibody against GST (Santa Cruz Biotechnology, CA, USA); antibodies against Akt serine 473 (S473) and pan Akt (Epitomics, CA, USA); antibody against HA (Covance, NJ, USA); antibody against FLAG (Sigma, MO, USA); horseradish peroxidase anti-rabbit (Jackson, PA, USA); and anti-mouse secondary antibody (Jackson, PA, USA). The antibodies against mTOR, Raptor, and mLST8 have been described previously [32]. The antibodies against Rictor and $\mathrm{mSin} 1$ were respectively generated by introducing DNA fragments into the pGEX GST plasmid corresponding to aa 1508-1708 of
Rictor and aa 314-522 of mSin1 and expressing them in the BL21(DE3) pLysS strain of E. coli. The proteins were purified using GSH agarose and the two eluates were then used as antigens to immunize rabbits. The injection and maintenance of rabbits were executed by Cocalico Biologicals, Inc (Reamstown, PA, USA). The same fragments of Rictor and mSin 1 were also cloned individually into the PinPointXa vector (Promega, WI, USA) to generate biotinylated proteins in bacteria. The antibodies in rabbit sera were affinity purified using the biotin-avidin resin system by following the manufacturer's instruction (Promega, WI, USA). All other chemicals were purchased from Sigma (MO, USA) unless otherwise indicated.

\section{Plasmid construction}

The mouse Sin1 gene was subcloned from a cDNA clone (MGC:106246, IMAGE: 6392317) into a series of different mammalian expression vectors after PCR in which the 5' primer used GAATTCTATGGCCTTCTTGGACAATCCAACT and the 3' primer used GCGGCCGCTCACTGCTGCCCTGATTT CTTCTC. The wild-type and various mutants of mTOR, Rictor, mSin1, Ras and Akt genes were also subcloned into a series of different mammalian expression vectors. Each of these vectors produces proteins containing different types of tag, namely FLAG, HA, and GST. All the constructs were confirmed by DNA sequencing.

\section{Cell culture and transfection}

HEK 293T cells were cultivated in DMEM supplemented with $10 \% \mathrm{FBS}$ and penicillin/streptomycin in a $5 \% \mathrm{CO}_{2}$ at $37^{\circ} \mathrm{C}$ in an incubator. When transfection was performed, the cells were plated at a density of $3.5 \times$ $10^{6}$ per $10 \mathrm{~cm}$ dish and transfected $5 \mathrm{~h}$ later using a total of $10 \mu \mathrm{g}$ of DNA and $30 \mu \mathrm{l}$ of Lipofectamine per dish by following the manufacturer's instructions (Invitrogen, CA, USA). Drop-wise addition of the DNA mixture onto each $10 \mathrm{~cm}$ dish was executed and then the dishes were incubated for additional 36 to $48 \mathrm{~h}$.

\section{Cell lysis, immunoprecipitation, and Western blotting}

Frozen HEK 293T cells was lysed in the lysis buffer (20 mM Tris base, $\mathrm{pH} 7.9,20 \mathrm{mM} \mathrm{NaCl}, 1 \mathrm{mM}$ EDTA, 5 mM EGTA, $20 \mathrm{mM} \beta$-glycerophosphate, $1 \mathrm{mM}$ dithiothreitol, $1 \mathrm{mM}$ phenylmethylsulfonyl fluoride, 25 $\mathrm{nM}$ calyculin A, $0.25 \%$ (w/w) CHAPS, 1 tablet $/ 50 \mathrm{ml}$ of protease inhibitor (Roche Molecular Biochemicals)). Next, $2 \mu \mathrm{g}$ of IgG, Rictor, Raptor or FLAG antibodies were mixed with protein $\mathrm{A} / \mathrm{G}$-agarose at $4^{\circ} \mathrm{C}$ for $1 \mathrm{~h}$ and then washed three times in lysis buffer. The cell lysates were centrifuged at 13,500 rpm for $10 \mathrm{~min}$ and aliquots of the supernatants, containing equal amounts of protein 
as measured by Bradford assay (Bio-Rad), were added to $15 \mu \mathrm{l}$ of settled antibodies-agarose beads and incubated at $4^{\circ} \mathrm{C}$ for $2 \mathrm{~h}$. The beads were washed three times with $1 \mathrm{ml}$ of lysis buffer, twice with $1 \mathrm{ml}$ of lysis buffer containing $0.5 \mathrm{M} \mathrm{NaCl}$, and then once with $1 \mathrm{ml}$ of lysis buffer. Finally the adsorbed proteins were released using SDS sample buffer and incubation at $95^{\circ} \mathrm{C}$ for $10 \mathrm{~min}$. The released proteins were separated by SDS-polyacrylamide gel electrophoresis (SDS-PAGE) followed by transferring onto a polyvinylidene difluoride (PVDF) membrane. The various membranes were probed with the appropriate specific antibodies as indicated. The blots were visualized using horseradish peroxide-conjugated secondary antibody followed by chemiluminescence using the manufacturer's protocol (Millipore, MA, USA).

\section{RNAi viral particle preparation}

For RNAi viral particle preparation, bacterial clones or plasmids containing short hairpin RNA oligonucleotides of the target genes were obtained from the National RNAi Core Facility (Genomic Research Center, Academia Sinica, Taipei, Taiwan) and have been partially described previously [33]. The functional clones and corresponding effective target sequences of the control, of Raptor, of Rictor, and of mSin 1 were verified and are: luciferase (control), 5'CGCTGAGTACTTCGAAATGTC, Raptor sequence, 5'GGCTAGTCTGTTTCGAAATTT, Rictor sequence, 5'ACTTGTGAAGAATCGTATCTT, the mSin 1 508s1c1 sequence 5'CAGTCGATATTACCTCAAGTT, and another mSin 1 1566s $1 \mathrm{cl}$ sequence 5'CTAAGCAATCACGACTATAAA. The RNAi plasmids were co-transfected with two other viral packaging plasmids, pCMV8.91 and pMD.G, into the HEK 293T cells. The virus-containing medium was collected after transfection for $40 \mathrm{~h}$ and concentrated by ultracentrifugation at 25,000 rpm for $4 \mathrm{~h}$. The pellets were then dissolved in PBS buffer and stored at $-80^{\circ} \mathrm{C}$ until use.

\section{Author contributions}

C.A.Y., conception and design, collection and assembly of data, data analysis and interpretation; S.O.V., conception and design, collection and assembly of data, data analysis and interpretation; Y.Y.S., collection and assembly of data, data analysis and interpretation; C.T.C., data analysis and interpretation; J.H.C., collection and assembly of data; Y.L., conception and design, collection and assembly of data, data analysis and interpretation, financial support, manuscript writing.

\section{ACKNOWLEDGMENTS}

This work was partly supported by a grant from the Office of Research and Development (103A02) of National Taiwan Normal University (NTNU) Taiwan to
Y. Lin. Publication of this article was also subsidized by NTNU, Taiwan.

\section{CONFLICTS OF INTEREST}

The authors declare no potential conflicts of interest.

\section{REFERENCES}

1. Albert V, Hall MN. mTOR signaling in cellular and organismal energetics. Curr Opin Cell Biol. 2015; 33:55-66.

2. Ong PS, Wang LZ, Dai X, Tseng SH, Loo SJ, Sethi G. Judicious toggling of mTOR activity to combat insulin resistance and cancer: current evidence and perspectives. Front Pharmacol. 2016; 7:395.

3. Saxton RA, Sabatini DM. mTOR Signaling in growth, metabolism, and disease. Cell. 2017; 168:960-976.

4. Leontieva OV, Blagosklonny MV. Gerosuppression by panmTOR inhibitors. Aging (Albany NY). 2016; 8:3535-3551.

5. Leontieva OV, Demidenko ZN, Blagosklonny MV. Dual mTORC1/C2 inhibitors suppress cellular geroconversion (a senescence program). Oncotarget. 2015; 6:23238-23248. doi: 10.18632/oncotarget.4836.

6. Malagelada C, Jin ZH, Jackson-Lewis V, Przedborski S, Greene LA. Rapamycin protects against neuron death in in vitro and in vivo models of Parkinson's disease. J Neurosci. 2010; 30:1166-1175.

7. Park H, Garrido-Laguna I, Naing A, Fu S, Falchook GS, Piha-Paul SA, Wheler JJ, Hong DS, Tsimberidou AM, Subbiah V, Zinner RG, Kaseb AO, Patel S, et al. Phase I dose-escalation study of the mTOR inhibitor sirolimus and the HDAC inhibitor vorinostat in patients with advanced malignancy. Oncotarget. 2016; 7:67521-67531. doi: 10.18632/oncotarget.11750.

8. Soliman GA, Steenson SM, Etekpo AH. Effects of metformin and a mammalian target of rapamycin (mTOR) ATP-competitive inhibitor on targeted metabolomics in pancreatic cancer cell line. Metabolomics (Los Angel). 2016; 6:2153-0769.

9. Garcia-Martinez JM, Alessi DR. mTOR complex 2 (mTORC2) controls hydrophobic motif phosphorylation and activation of serum- and glucocorticoid-induced protein kinase 1 (SGK1). Biochem J. 2008; 416:375-385.

10. Hresko RC, Mueckler M. mTOR. RICTOR is the Ser473 kinase for Akt/protein kinase B in 3T3-L1 adipocytes. J Biol Chem. 2005; 280:40406-40416.

11. Li X, Gao T. mTORC2 phosphorylates protein kinase Czeta to regulate its stability and activity. EMBO Rep. 2014; 15:191-198.

12. Sarbassov DD, Guertin DA, Ali SM, Sabatini DM. Phosphorylation and regulation of Akt/PKB by the rictormTOR complex. Science. 2005; 307:1098-1101. 
13. Frias MA, Thoreen CC, Jaffe JD, Schroder W, Sculley T, Carr SA, Sabatini DM. mSin1 is necessary for Akt/PKB phosphorylation, and its isoforms define three distinct mTORC2s. Curr Biol. 2006; 16:1865-1870.

14. Jacinto E, Facchinetti V, Liu D, Soto N, Wei S, Jung SY, Huang Q, Qin J, Su B. SIN1/MIP1 maintains rictor-mTOR complex integrity and regulates Akt phosphorylation and substrate specificity. Cell. 2006; 127:125-137.

15. Yang Q, Inoki K, Ikenoue T, Guan KL. Identification of Sin1 as an essential TORC2 component required for complex formation and kinase activity. Genes Dev. 2006; 20:2820-2832.

16. Wilkinson MG, Pino TS, Tournier S, Buck V, Martin H, Christiansen J, Wilkinson DG, Millar JB. Sin1: an evolutionarily conserved component of the eukaryotic SAPK pathway. EMBO J. 1999; 18:4210-4221.

17. Cheng J, Zhang D, Kim K, Zhao Y, Su B. Mip1, an MEKK2-interacting protein, controls MEKK2 dimerization and activation. Mol Cell Biol. 2005; 25:5955-5964.

18. Schroder W, Bushell G, Sculley T. The human stressactivated protein kinase-interacting 1 gene encodes JNKbinding proteins. Cell Signal. 2005; 17:761-767.

19. Schroder WA, Buck M, Cloonan N, Hancock JF, Suhrbier A, Sculley T, Bushell G. Human Sin1 contains Ras-binding and pleckstrin homology domains and suppresses Ras signalling. Cell Signal. 2007; 19:1279-1289.

20. Cameron AJ, Linch MD, Saurin AT, Escribano C, Parker PJ. mTORC2 targets AGC kinases through Sin1-dependent recruitment. Biochem J. 2011; 439:287-297.

21. Wang SZ, Roberts RM. The evolution of the Sin1 gene product, a little known protein implicated in stress responses and type I interferon signaling in vertebrates. BMC Evol Biol. 2005; 5:13.

22. Takahara T, Hara K, Yonezawa K, Sorimachi H, Maeda T. Nutrient-dependent multimerization of the mammalian target of rapamycin through the N-terminal HEAT repeat region. J Biol Chem. 2006; 281:28605-28614.

23. Sarbassov DD, Ali SM, Kim DH, Guertin DA, Latek RR, Erdjument-Bromage H, Tempst P, Sabatini DM. Rictor, a novel binding partner of mTOR, defines a rapamycininsensitive and raptor-independent pathway that regulates the cytoskeleton. Curr Biol. 2004; 14:1296-1302.

24. Lee S, Parent CA, Insall R, Firtel RA. A novel Rasinteracting protein required for chemotaxis and cyclic adenosine monophosphate signal relay in Dictyostelium. Mol Biol Cell. 1999; 10:2829-2845.

25. Schroder W, Cloonan N, Bushell G, Sculley T. Alternative polyadenylation and splicing of mRNAs transcribed from the human Sin1 gene. Gene. 2004; 339:17-23.

26. Ikenoue $\mathrm{T}$, Inoki $\mathrm{K}$, Yang $\mathrm{Q}$, Zhou $\mathrm{X}$, Guan KL. Essential function of TORC2 in PKC and Akt turn motif phosphorylation, maturation and signalling. EMBO J. 2008; 27:1919-1931.

27. Lee S, Comer FI, Sasaki A, McLeod IX, Duong Y, Okumura K, Yates JR, 3rd, Parent CA, Firtel RA. TOR complex 2 integrates cell movement during chemotaxis and signal relay in Dictyostelium. Mol Biol Cell. 2005; 16:4572-4583.

28. Yuan Y, Pan B, Sun H, Chen G, Su B, Huang Y. Characterization of $\sin 1$ isoforms reveals an mTORdependent and independent function of Sin1gamma. PLoS One. 2015; 10:e135017.

29. Boucher J, Kleinridders A, Kahn CR. Insulin receptor signaling in normal and insulin-resistant states. Cold Spring Harb Perspect Biol. 2014; 6:a00919.

30. Alessi DR, James SR, Downes CP, Holmes AB, Gaffney PR, Reese CB, Cohen P. Characterization of a 3-phosphoinositidedependent protein kinase which phosphorylates and activates protein kinase Balpha. Curr Biol. 1997; 7:261-269.

31. Fresno Vara JA, Casado E, de Castro J, Cejas P, BeldaIniesta C, Gonzalez-Baron M. PI3K/Akt signalling pathway and cancer. Cancer Treat Rev. 2004; 30:193-204.

32. Long X, Lin Y, Ortiz-Vega S, Yonezawa K, Avruch J. Rheb binds and regulates the mTOR kinase. Curr Biol. 2005; 15:702-713.

33. Chen WY, Lin CL, Chuang JH, Chiu FY, Sun YY, Liang $\mathrm{MC}$, Lin $\mathrm{Y}$. Heterogeneous nuclear ribonucleoprotein $\mathrm{M}$ associates with mTORC2 and regulates muscle differentiation. Sci Rep. 2017; 7:41159. 